\title{
Developing guidelines for brownfield development in South Africa
}

\author{
L. Potts \& C. E. Cloete \\ Department of Construction Economics, \\ University of Pretoria, South Africa
}

\begin{abstract}
In contrast to guidelines and comprehensive policies for brownfield development in the UK and the USA, no reference to brownfields is made in any of the current legislation or policies of South Africa.

The objective of the research was firstly to develop an appropriate definition for brownfields in the South African context and secondly to propose guidelines for redevelopment of brownfields in South Africa.

A possible definition and a set of guidelines were tested against the perceptions and opinions of stakeholders. Based upon the literature study and responses to the questionnaire, both a definition and a set of guidelines for the South African context are proposed.

It is concluded that further research is required and that policies need to be generated in order to firstly come to agreement on a definition of brownfields and secondly to finalize development guidelines. These have to be incorporated into the existing development policies. The research also indicated that it is necessary for an inventory of brownfields to be established by local authorities in order to start the process of brownfield development in South Africa.
\end{abstract}

Keywords: brownfields, South Africa, guidelines, policies.

\section{Introduction}

World-wide, brownfields sites offer considerable potential for development. The number of sites suspected of being contaminated is estimated to be between 900,000 and 1,500,000 in Europe and 50,000 to 100,000 in the UK [1], while there are an estimated 600,000 brownfield sites in the United States [2]. 
Brownfield development is a way of ensuring that all available land in urban areas is developed and redeveloped to its full potential (see e.g. [3-6]). Some other benefits of brownfield redevelopment are [7, 8]

reduction of urban sprawl

reduction of health and environmental risks by encouraging site cleanup

full utilisation of existing infrastructure and traffic systems

greenfields remain usable for open space or agricultural use; and

the local tax base is increased.

As South African cities become more mature and urbanisation, population growth, development pressure and infrastructure costs continue to increase, the possible role of brownfield redevelopment was investigated as a strategy of promoting sustainable development of cities in South Africa. However, the current legislation and policies of South Africa do not contain any reference to brownfields.

The aim of this research was therefore to create a body of knowledge on the subject of brownfield development for South African use.

\section{Methodology}

An extensive literature review was undertaken in order to define a body of knowledge on first the various definitions of brownfields and second the guidelines for brownfield development.

Guided by the literature review, in particular [9, 10] potential groups of stakeholders were identified in the South African context. These comprised the following categories (number of stakeholders in that category in brackets): Current owners (30); Current Owner and Statutory requirements (13); Statutory Requirements (7); Legal, Scientific and technical (20). The opinions of community shareholders were not canvassed because of the paucity and the fragmented nature of formalised community shareholders.

A questionnaire was used to gather information of the current state of brownfield development in South Africa and to test the proposed definition and guidelines with the South African role players with a view for the definition and the guidelines to be verified. Questionnaires were sent to representatives of the various private as well as public sector stakeholders identified in the various stakeholder groups. From the 138 questionnaires that were sent out, only 23 completed questionnaires were received back. A number of respondents declined to complete the questionnaire as they were not aware of the term "brownfields" and were not in a position to complete the questionnaire. This is another strong indication that relevant stakeholders are not aware of brownfield redevelopment and its associated benefits and underscores the importance of this study.

Various discussions and interviews were held with identified role players in order to supplement the research. 


\section{Research findings}

The majority (79\%) of the respondents were from the private sector. Most of the public sector stakeholders that were asked to take part in the research did not respond, even though extra care was taken to invite more public stakeholders as it was anticipated that a poor response would be realised. The data below will therefore be mostly representative from the private sector.

\subsection{Brownfields register or inventory}

The majority of respondents $(70 \%)$ did not have access to a brownfields register. It was also found that only in a limited number of cases could the respondents who claimed to have a brownfield register give the actual size of the brownfields areas. Therefore the actual number of respondents who had access to a register is in fact much lower. In most cases the register that was referred to was, in fact, a register of all properties and not necessarily brownfields sites.

\subsection{Guidelines for brownfield development}

The majority (78\%) of respondents did not have guidelines and policies in place for brownfield development. Again, all the respondents who claimed to have guidelines and policies could not really elaborate on these and it seems that most were only part of general development procedures and policies and not specifically related to brownfields.

\subsection{Total size of brownfields area}

In an effort to establish the total extent of brownfields in South Africa, respondents were asked to state the total size of brownfields area under their control. However, only $20 \%$ of the respondents were able to give the extent of brownfield development that was listed in their asset registers. The total size of brownfields as captured in this research is 60,202 Ha. This includes mostly private land; public land was excluded due to the paucity of respondents from the public sector. The register includes mining land and some other privately owned major land holdings and is mainly situated in Gauteng. However, this is not an indication of the total amount of brownfield development in South Africa as only a very small part was sampled.

If one considers that there is not a common definition for brownfields that is used in South Africa, it is almost impossible to estimate the total extent as there is not one classification system and one can therefore not rely on the data as provided by the respondents as they might not all have used the same classification system.

The only accurate way of measuring the total extent would be to firstly define brownfields and secondly, to establish an inventory of brownfields. 


\subsection{The benefits of brownfield development}

Most respondents identified density increase as the most important benefit associated with brownfield development followed by the reuse of infrastructure, urban sprawl reduction, and new economic opportunities. Reduction of health risk, crime and environmental risk was seen as least important with the increase in property value, tax base and job creation being moderately important.

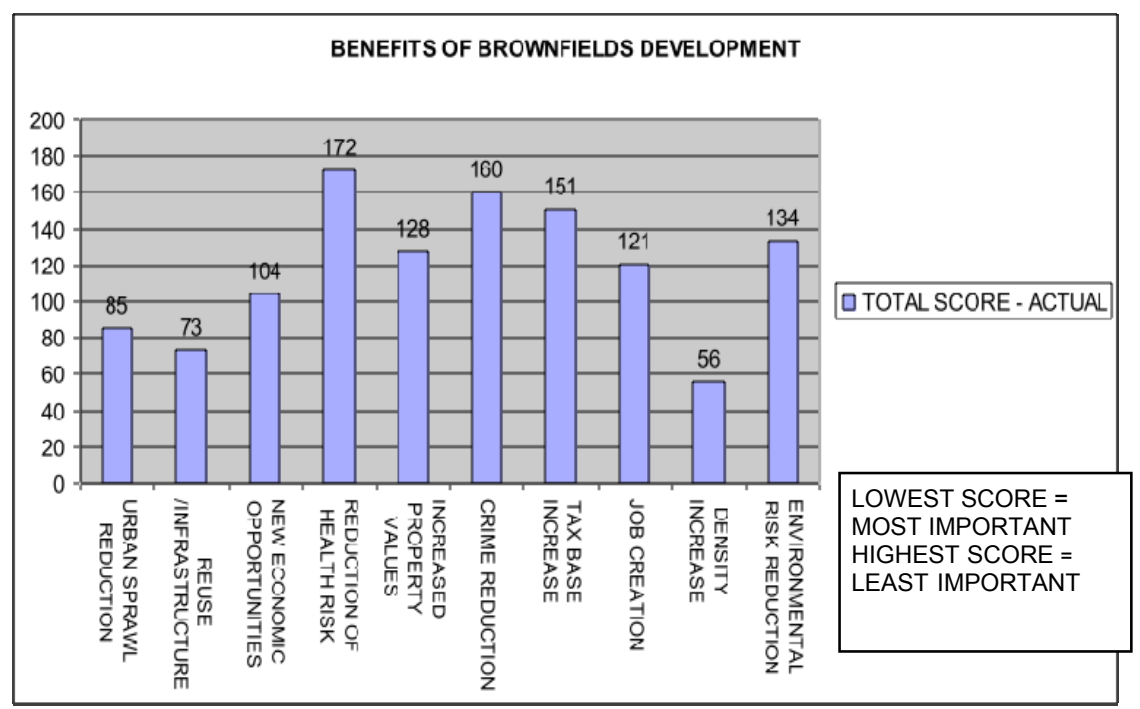

Figure 1: $\quad$ Perceived benefits of brownfield development.

The findings are very interesting if one considers that these responses are mainly from the private sector. It seems that the private sector identifies benefits that should normally be of priority to the public sector as it involves strategic benefits on a greater scale and not necessarily direct benefits to the private sector. This would indicate that stakeholders in the private sector do have a good understanding of the possible benefits associated with brownfield redevelopment. One could therefore conclude that the private sector would have significant input in the redevelopment process and that they will see the benefits associated with brownfield redevelopment.

\subsection{Who should be responsible for brownfield development?}

When analysing the 58 responses regarding who should be responsible for brownfield development, the following was found: The majority of the respondents $(31 \%)$ stated that both the local government and the private sector should be responsible for brownfield redevelopment. A large number $(28 \%)$ stated that provincial government should be responsible. Only a small percentage $(12 \%)$ stated that national government should be responsible. Again it is very 
interesting that $29 \%$ indicated that the private sector should be responsible for brownfield development, indicating a commitment from the private sector to brownfield redevelopment. This finding is in line with the international literature where this responsibility to implement brownfields is mainly shared between the local government and private sector.

\subsection{Elements of a definition for brownfields in South Africa}

The respondents were asked to rank in order of importance the elements that should be included in the definition for brownfields. The responses as set out in Figure 2 were as follows: Greenfields was scored the lowest by the respondents followed by urban area, vacant, environmental contamination and industrial derelict land, previously developed, underused and abandoned scored the highest, while commercial and buildings scored slightly lower.

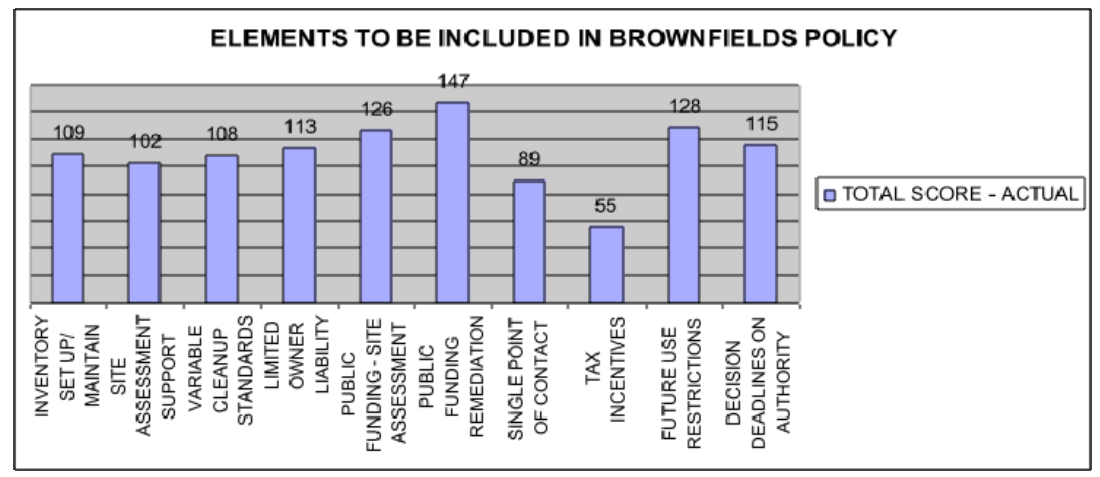

Figure 2: Elements to be included in the definition of brownfield development.

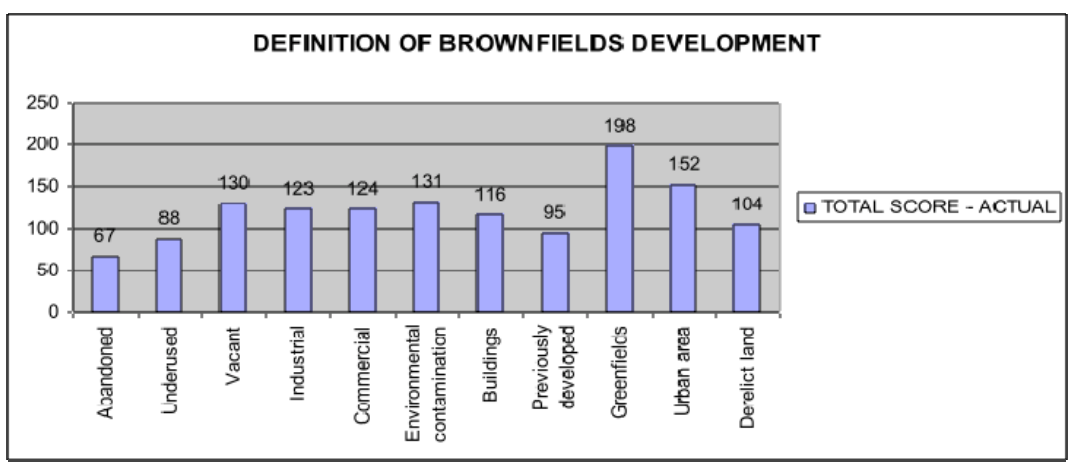

Figure 3: Elements to be included in brownfields policy.

The responses again indicate that the private sector identifies urban redensification as an important element of brownfields. By identifying vacant, 
abandoned, underused and previously developed as some of the important elements the respondents also indicated by implication that previously developed or derelict are important elements to be included in the South African definition.

\subsection{Elements to be included in a brownfield development policy}

When analysing the responses regarding the elements to include into a brownfield redevelopment programme, the following was found:

Public funding of remediation scored the lowest, followed by future use restrictions and public funding of site assessment and limited owner liability.

This indicates that the private sector identifies that the public sector will have to provide assistance by establishing incentives for the private sector to develop brownfields. By scoring future use restrictions as low, the respondents acknowledges that a practical approach should be adopted in setting up clean up standards. Variable and risk-based clean up standards, decision deadline on authorities and inventory set up also scored low by the respondents, while assessment support and single point of contact was scored slightly higher. Tax incentives were scored the highest with a large margin. Indicating that the respondents believed that tax incentives would be an appropriate element to include into a brownfield redevelopment programme.

\subsection{Conclusion}

In general the analysis of the data indicates that very little understanding of brownfield redevelopment exists with the relevant stakeholders. It further indicates that no policies or guidelines exist to govern or guide brownfield redevelopment. No evidence of a brownfields inventory could be found during this research, which in turn makes it very difficult to assess the total extent of brownfields. There is also no common definition for brownfield redevelopment in South Africa.

The research did however find that the private sector is most committed to and interested in brownfield redevelopment and most closely identifies with the benefits associated with brownfield redevelopment.

The research also indicated that financial assistance would be required from the public sector in order to facilitate brownfield redevelopment and that both the private and local government has a major role to play in brownfield redevelopment. As stated previously, responses were mainly received from the private sector and the data is therefore mostly representative of the private sector.

\section{Proposed definition}

When considering the extensive international literature review and the research that was undertaken, one can conclude that it is essential to set out a common definition of the term brownfields. In proposing a definition, it is important that the South African context is taken into consideration in order to ensure that the proposed definition is broad enough to cover all relevant aspects. 
It is clear that there already exist various accepted categories of land use, for example, vacant, derelict, and statutory contaminated land, which impinge on the definition of brownfield, and that this has the potential to cause confusion.

Taking into account the factors related to brownfield in the South African context, and the internationally accepted definitions of brownfields, the following definition for South African usage is proposed: "a brownfield site is infill land or premises where remedial action is required prior to redevelopment. It may also be vacant, derelict or contaminated. No specific land use is attributed."

Infill is defined as per NEMA - the National Environmental Management Act 107 of 1998 [11] - "urban development, including residential, commercial, retail, institutional, educational and mixed use development, but excluding industrial development, in a built up area which is at least 50 percent abutted by urban development and which can be readily connected to municipal bulk infrastructure services."

Vacant is defined as "all land that is not used efficiently or to its best potential in terms of its zoning and locality."

Derelict is defined as per NEMA as "abandoned land or property where the lawful or legal land use rights have not been exercised during the preceding ten year period."

Contaminated is defined as per NEMA as "the presence in or under any land, site, buildings, or structures of a substance or micro-organism above the concentration that is normally present in or under the land, which substance or micro-organisation directly or indirectly affects or may affect the quality of soil or the environment adversely."

\section{Proposed guidelines for brownfield development}

The proposed guidelines below are purely based on the international literature, although cognisance was taken of the findings of the research. However, as stated previously, brownfield development is a fairly unknown field of study in the South African context and it is therefore necessary to rely heavily on the international literature.

The following guidelines are proposed:

\subsection{Definition}

A common definition of the term brownfields needs to be adopted by the various authorities. It is recommended that this definition is set out in national environmental legislation in order to standardise future classifications. It is further proposed that the definition as set out in the previous section of this report be adopted.

\subsection{Policy and legislation}

Local authority planning policies need to be updated in order to include a relevant policy on brownfield development. Each local authority should set out 
brownfield redevelopment as a priority. The following elements should be addressed as part of the policies:

Definition - the policy document needs to set out the definition that is applicable. It is proposed that the definition as set out previously be adopted. The various elements of the definition will also have to be set out and the definitions of these should also be given.

Background and introduction - the policy document needs to set out the context of the local authority area as well as the context of brownfield redevelopment from a broader context. The existing policies and priorities that are set out in the local authority policy documents will be used as a basis and brownfield redevelopment needs to be identified as a method for achieving some of the strategic priorities that the authority have set previously.

The typical priorities must include

- Achieving higher density developments;

- $\quad$ Ensuring that development is concentrated within an urban edge and that urban sprawl is discouraged;

- $\quad$ Redeveloping the inner city;

- $\quad$ Maximising the use of existing infrastructure;

- $\quad$ Providing optimal public transport;

- $\quad$ Providing housing that is situated close to work opportunities;

- $\quad$ Remediation of contaminated land; and

- $\quad$ Fostering sustainable developments.

Community profiling - it is proposed that the local authority set out a profile of the socio-economic history, environmental issues, setting out the demography, identifying cultural and heritage resources, and the economic basis of their area. A number of the above studies will already be available as most of it makes part of the current development policies that exist within the various authorities.

Public participation - a process of public participation as set out in NEMA is proposed. This process should aim to involve stakeholders in order to ensure that the various stakeholders are committed to the process of brownfield redevelopment.

Special unit - it is proposed that a unit is set up with the authority to deal with brownfield development. This unit should be responsible to set out the brownfields policies, to conduct the public participation and to provide resources as part of the brownfield redevelopment process. The unit will also be responsible to coordinate and facilitate the inter-governmental interface that would be required for this process.

\subsection{Inventory}

In order to set up a successful brownfield redevelopment process, one of the critical elements is the site identification, characterisation and prioritisation - see e.g. $[12,13]$. The accuracy of the above process is a critical element in the success of such a programme. It is proposed that the following aspects be included in the proposed inventory:

- $\quad$ Site Location

- $\quad$ Site Boundaries 


$\begin{array}{ll}\text { - } & \text { Site Size } \\ \text { - } & \text { Land Use } \\ \text { - } & \text { Zoning } \\ \text { - } & \text { Owevious Land Use } \\ \text { - } & \text { Ownership Contact Details } \\ \text { - } & \text { Nature of Contamination } \\ \text { - } & \text { Eroundwater Contamination } \\ \text { - } & \text { Infrastructure Requirements } \\ \text { Potential Cost of Remediation } \\ \text { Geotechnical Conditions. }\end{array}$

Most of the above data will already exist on the GIS of the various authorities and further data can be obtained from the various public electronic data bases, for example the Deeds Office, the Surveyor General, the Gauteng Department of Agriculture and Rural development, the Department of Environmental Affairs and Development.

Public participation will play a big role during this part of the exercise as the involvement of the private sector is critical at this stage. A list of stakeholders needs to be set up by the local authority in order to identify the relevant stakeholders.

\subsection{Incentives and project funding and finance}

Local authorities need to assess based on the created inventory, what level of incentives they will make available and which areas they will prioritise. A development roll-out plan needs to be set out in their planning policies.

Various incentives should be considered. However, from the research it became apparent that tax breaks were not seen as being a preferred option for the private sector. This would have to be researched further and should be looked at during the public participation process as this is currently the incentive that is mostly used by the authorities to promote inner city development and seems to be the most practical solution in the South African context.

The various project funding methods should be investigated and a funding model should be set up. Private Public Partnerships (PPPs) should be considered as this method would ensure commitment, expertise and resources from both the public and the private sector. PPPs have, however, their own risks associated and these also need to be managed.

\subsection{Risks}

It is necessary for each authority to identify the various risks that might be associated with their specific areas and to set out a plan on how to deal with these risks. Risks could include:

- $\quad$ Environmental risks

- $\quad$ Time and cost overruns 
- $\quad$ Diminished property values

- Socio-economic changes

- Community involvement

- Inter-governmental facilitation

- $\quad$ Resource availability and

- $\quad$ Funding risks.

\subsection{Implementation}

A development plan setting out the initiation of the project, the planning of the project, the evaluation of the project, the strategy of the project and the implementation of the project needs to be drawn up in order to initiate implementation. Guidelines in this regard are provided by various authors [14-17].

\section{Conclusions and recommendations}

A suitable definition of "brownfields" that can be used in the South African context has been proposed. The proposed definition was tested and verified.

Secondly, guidelines for brownfield development in South African were proposed. The proposed guidelines were tested and verified as part of the research where the responses were analysed in order to deduce elements that should be included in the guidelines.

Thirdly, the number of brownfields sites in South Africa could not be established, as it was found that no inventories exist.

It is recommended that the definition of brownfield development as set out in this research be adopted.

It is further recommended that the guidelines as set out in this research be used as a basis for further study and that the authorities attempt to set out brownfields policies and guidelines.

A further recommendation is made that the authorities in South Africa start the process of setting up a brownfields inventory.

\section{References}

[1] Thornton, G., Franz, M., Edwards, D., Pahlen, G. and Nathanail, P. The challenge of sustainability: incentives for Brownfield regeneration in Europe. Environmental Science and Policy, 10, pp. 116-134, 2007.

[2] Hoffman, C. and Harasimowicz, J. One stop shopping. Urban Land, June 2006, pp. 113-114.

[3] Alberini, A., Loongo, A., Tonin, S., Trombetta, F. and Turvani, M. The role of liability, regulation and economic incentives in brownfield remediation and redevelopment: evidence from surveys of developers. Regional Science and Urban Economics, 35, pp. 327-351, 2005.

[4] Grimski, D. and Ferber, U. Urban brownfields in Europe. Land Contamination and Reclamation, 9(1), pp. 143-148, 2001. 
[5] Meyer, P. B. and Van Landingham. Reclamation and Economic Regeneration of brownfields. Reviews of Economic Development Literature and Practice: No. 1. Award No: 99-07-13803.00, 2000.

[6] Raco, M. and Henderson, S. Sustainable urban planning and the brownfield development process in the United Kingdom: Lessons from the Thames Gateway. Local Environment, 11(5), pp. 499-513, 2006.

[7] De Sousa, C. Policy Performance and Brownfield Redevelopment in Milwaukee, Wisconsin. The Professional Geographer, 57(2), pp. 312-327, 2005.

[8] De Sousa, C. Urban brownfields redevelopment in Canada: the role of local government. The Canadian Geographer, 50(3), pp. 392-407, 2006.

[9] Platinum International. A sustainable brownfields model framework. US Environmental Protection Agency, Washington, DC, 1999.

[10] Alker, S., Joy, V., Roberts, P. and Smith, N. The definition of brownfield. Journal of Environmental Planning and Management, 43(1), pp. 49 - 69, 2000.

[11] Republic of South Africa, Regulations for the National Environmental Management Act 107 of 1998. Cape Town: Government Printer, 2008.

[12] Coffin A. L. and Meyer P. B. Closing the brownfield information gap: Practical methods for identifying brownfields, Practical guide \#3, Southeast regional Environmental Finance centre, University of Louisville. (No date cited).

[13] Syms P. Redeveloping Brownfield land - the decision making process. Journal of Property Investment and Finance, 17(5), p. 481, 1999.

[14] Edwards A. L. Brownfields redevelopment initiatives. The Practical Real Estate Lawyer, 19(2), pp. 47-57, 2003.

[15] Edmunds J. The brownfields redevelopment: Green building opportunity. Land development, Summer 2006, pp. 30-35.

[16] Thomas M. R. A GIS-based decision support system for brownfield redevelopment. Landscape and Urban Planning, 58(2002), pp. 7-23, 2002.

[17] Van Rooyen, E. Integrated development and the brownfields phenomena. Journal of Public Administration 3(1), pp. 61-80, 2001. 